\title{
Magnetic Resonance Spectroscopy for Prediction of Grades of Diffusely Infiltrating Intracranial Astrocytomas
}

\author{
Obaida Abu ${ }^{1}$ Asifur Rahman ${ }^{1}$ Robert Khan ${ }^{1}$ Shamsul Alam¹ Kanak Barua ${ }^{1} \quad$ Bipin Chaurasia
}

\author{
${ }^{1}$ Department of Neurosurgery, Bangabandhu Sheikh Mujib Medical \\ University, Dhaka, Bangladesh
}

Address for correspondence Bipin Chaurasia, MS, Department of Neurosurgery, Bangabandhu Sheikh Mujib Medical University, Dhaka 1000, Bangladesh (e-mail: trozexa@gmail.com).

J Neurosci Rural Pract 2020;11:581-584

\begin{abstract}
Keywords

- magnetic resonance spectroscopy (MRS)

- diffusely infiltrating astrocytomas

- N-acetyl aspartate (NAA)

- choline/creatine $(\mathrm{Ch} /$ $\mathrm{Cr}$ ) ratio

Objective Gliomas, the most frequent primary brain tumors, have various grades, among which grade II, III, and IV are diffusely infiltrating astrocytomas. As therapeutic approaches and outcome differ considerably, depending on the grade of these tumors, prediction is important regarding outcome. Magnetic resonance spectroscopy (MRS) can be of help in understanding of the biochemical changes of pathological state to study, monitor, predict grading and outcome of gliomas.

Materials and Methods All the 30 patients in the study with intracranial diffusely infiltrating astrocytoma had MRS study using 1.5 Tesla MR scanner. The study population was divided into three groups on the basis of the grades of the tumor according to histopathology. Mean height of choline (Ch), $\mathrm{N}$-acetyl aspartate (NAA), creatine ( $\mathrm{Cr}$ ) peak, and choline/creatine $(\mathrm{Ch} / \mathrm{Cr})$ ratio was documented. Mean value of each variable among three grades was analyzed and compared with analysis of variance (ANOVA) test (F-test).

Results There was positive relationship regarding $\mathrm{Ch} / \mathrm{Cr}$ ratio among astrocytomas grade II to IV and the result was significant $(p=0.047)$. A positive relationship of $\mathrm{Ch}$ peak was also observed for grade II to IV astrocytoma, though the result was not significant $(p=0.578)$. The result was nonsignificant for NAA $(p=0.696)$ and $\operatorname{Cr}(p=0.740)$ peak also.

Conclusion We recommend $\mathrm{Ch} / \mathrm{Cr}$ ratio to be considered as a dependable MRS data to comment on low- or high-grade astrocytomas. MRS can be done as a routine investigation in the developing countries for astrocytomas where other facilities are less accessible for reliable prediction and counseling.
\end{abstract}

\section{Introduction}

Gliomas vary in cellular and nuclear pleomorphism, mitotic activity, vascular proliferation, and necrosis. These histologically heterogeneous group of tumors are the most frequent primary brain tumors. ${ }^{1}$

Owing to their infiltrative nature and high relapse rate, the prognosis of malignant gliomas is generally poor, even following aggressive treatment. ${ }^{1}$

Depending on clinicopathologic entities, diffuse astrocytomas, anaplastic astrocytomas and glioblastoma multiforme, which are World Health Organization (WHO) grade II, III, and IV respectively, are categorized as diffusely infiltrating astrocytomas. ${ }^{2}$

Based on the tumor grade, there are considerable differences in therapeutic approaches of gliomas. Thus, development of in vivo techniques to allow accurate determination of the grade of these tumors is important in deciding appropriate treatment. ${ }^{1}$

Among various imaging modalities, magnetic resonance imaging (MRI), is often the investigation of choice for its easy availability, pathophysiologic specificity, potential for repeat 
studies, and biosafety. Moreover, because of the contrast versatility, it can provide excellent soft tissue differentiation. ${ }^{3}$

Magnetic resonance spectroscopy (MRS), an additional modality available in most clinical MR scanners now, can detect relatively small molecules to assess cellular metabolism noninvasively. Therefore, this is the most convenient technique to study and monitor gliomas. ${ }^{3,4}$

MRS is more popular among clinicians, because of its capability to offer understanding of the biochemical changes of a pathological condition, in addition to delineation of anatomy and pathology. As a consequence of well-suited MRS properties, brain has been studied most by in vivo proton magnetic resonance spectroscopy (1H-MRS).,

Choline ( $\mathrm{Ch})$, creatine $(\mathrm{Cr}), \mathrm{N}$-acetyl aspartate (NAA), lactate (Lac), myo-inositol (Ins), glutamine (Gln), glutamate (Glu), lipids (Lip), and the amino acids leucine (Leu) and alanine (Ala) are the major brain metabolites that can be detected in MRS. ${ }^{7}$ A decrease in NAA and an increase in Ch-containing compounds are characteristic of gliomas. ${ }^{8}$

The present study explores the role of MRS to establish a correlation between the histological grading of astrocytoma and MRS findings, decision making for the management of the patient, and predicting prognosis in a resource-limited setting.

\section{Materials and Methods}

The present observational cross-sectional prospective study was performed in the Department of Neurosurgery of Bangabandhu Sheikh Mujib Medical University in the period between June 2010 and April 2012. Permission of institutional review board (Ethical committee) was obtained at the beginning of the study and informed written consent was taken from all participants or their guardians individually during the study. Thirty consecutive patients with intracranial diffusely infiltrating astrocytoma fulfilling the inclusion criteria were studied and MRS of all the participants were done with 1.5 T MRI/MRS (Signa HDxt 1.5T GEHCMRI) and multivoxel ${ }^{1}$ HMRS was also done. Priority was given to place voxel over most contrast up taking and/or solid portion of the tumor. Peritumoral areas were also investigated. During surgery, tumor specimen was collected and sent carefully for histopathology.

Finding of MRS relevant to study was documented. Spectrum of metabolic peaks was displayed chronologically: $\mathrm{Ch}, \mathrm{Cr}$, NAA, and Lac from higher to lower ppm. Data from most contrast up taking solid voxel was taken for analysis. After final pathologic diagnosis, based on histopathology, the study population/patients were grouped into three categories: astrocytoma grade II, III, and IV.

SPSS (Statistical Package for Social Science), version 19, software was used for statistical analysis. $p$-Value was set at $<0.05$ as statistically significant. Mean and standard deviation of each metabolic peak ( $\mathrm{Ch}, \mathrm{Cr}$, NAA) for each group of astrocytomas were measured. Metabolic ratios $(\mathrm{Ch} / \mathrm{Cr})$ were obtained. Data was given in SPSS program and analysis of variance (ANOVA) done.

\section{Results}

In the present study, grade IV astrocytoma was most common $(46.7 \%)^{9}$; followed by grade II astrocytoma, which was $33.3 \%{ }^{10}$; and grade III astrocytoma, which was $20 \%{ }^{6}$

In this study, mean of maximum $\mathrm{Ch}$ peak was found to be $95681.40 \pm 28937.386,110012.73 \pm 35996.049$, $114981.43 \pm 55179.821$ in grade II, III, and IV astrocytomas, respectively.

Mean of maximum NAA peak was found to be $43150.80 \pm$ $25629.136,36380.00 \pm 22857.029,49547.14 \pm 38877.517$ in grade II, III, and IV astrocytomas, respectively.

Mean of maximum $\mathrm{Cr}$ peak was found to be $50765.00 \pm 20743.957,52862.33 \pm 21386.090$, and 44997.86 \pm 26032.614 in grade II, III, and IV astrocytomas, respectively.

Mean of maximum $\mathrm{Ch} / \mathrm{Cr}$ ratio was found to be 1.9970 $\pm 0.41945,2.3117 \pm 1.06824,2.9607 \pm 1.07769$ in grade II, III, and IV astrocytomas, respectively.

Regarding $\mathrm{Ch} / \mathrm{Cr}$ ratio, there was positive relationship among grade II, III, and IV astrocytomas and the result was significant ( $p=0.047$ ) for spectroscopic data among grade II, III, and IV astrocytomas ( $p<0.05$; - Table 1 ).

A positive relationship of $\mathrm{Ch}$ peak was observed for grade II to IV astrocytoma, but the result was not significant $(p=0.578)$.

The result was found nonsignificant for NAA $(p=0.696)$ and $\operatorname{Cr}(p=0.740)$ peak also.

These results verify a significant relationship between preoperative data from ${ }^{1}$ HMRS and histological grading of diffusely infiltrating astrocytoma, supporting that ${ }^{1}$ HMRS can give valuable diagnostic information that cannot be achieved from conventional MRI alone, in assessing the grade of astrocytomas.

\section{Discussion}

Before onset of an effective treatment, differentiation between high and low grade astrocytomas is of utmost importance. $^{2-4}$ Predicting grade of tumors by conventional MRI can be difficult and unreliable. ${ }^{4,5}$ MRS, being a noninvasive method in detecting and grading of brain tumors, can help in diagnosis and grading of tumors more accurately. ${ }^{10-12}$

Significant changes with respect to tissue metabolites have been described in gliomas and in other brain tumors by means of ${ }^{1} \mathrm{HMRS}$ when compared with control subjects and other pathological brain alterations. In gliomas, especially higher Ch peaks and lower NAA peaks have been reported in relation to peaks from other metabolites, such as $\mathrm{Cr}^{11}$

Occurrence of diffusely infiltrating astrocytomas varies considerably in different studies. Although $80 \%$ of cases occurred around the age of 50 years, we did not find any particular age to be vulnerable for developing astrocytomas in this study. Mean age of occurrence of astrocytomas was 
Table 1 ANOVA for different MRS peaks in different histological grades of astrocytoma

\begin{tabular}{|c|c|c|c|c|c|c|}
\hline \multicolumn{2}{|c|}{ Source of variables } & \multirow{2}{*}{$\begin{array}{l}\text { Sum of squares } \\
2218000000.00\end{array}$} & \multirow{2}{*}{$\begin{array}{l}\mathrm{df} \\
2\end{array}$} & \multirow{2}{*}{$\begin{array}{l}\text { Mean square } \\
1109000000\end{array}$} & \multirow{4}{*}{$\begin{array}{l}F \text {-Value } \\
0.559\end{array}$} & \multirow{4}{*}{$\begin{array}{l}\text { Sig. ( } p \text {-Value) } \\
0.578\end{array}$} \\
\hline \multirow[t]{3}{*}{$\begin{array}{l}\text { Ch peak of } \\
\text { astrocytomas }\end{array}$} & $\begin{array}{l}\text { Between } \\
\text { groups }\end{array}$ & & & & & \\
\hline & $\begin{array}{l}\text { Within } \\
\text { groups }\end{array}$ & 53600000000.00 & 27 & 1985000000 & & \\
\hline & Total & 55820000000.00 & 29 & & & \\
\hline \multirow[t]{3}{*}{$\begin{array}{l}\text { NAA peak of } \\
\text { astrocytomas }\end{array}$} & $\begin{array}{l}\text { Between } \\
\text { groups }\end{array}$ & 768061963.886 & 2 & 384030981.943 & \multirow[t]{3}{*}{0.368} & \multirow[t]{3}{*}{0.696} \\
\hline & $\begin{array}{l}\text { Within } \\
\text { groups }\end{array}$ & 28172889959.314 & 27 & 1043440368.863 & & \\
\hline & Total & 28940951923.200 & 29 & & & \\
\hline \multirow[t]{3}{*}{$\begin{array}{l}\mathrm{Cr} \text { peak of } \\
\text { astrocytomas }\end{array}$} & $\begin{array}{l}\text { Between } \\
\text { groups }\end{array}$ & 337190612.419 & 2 & 168595306.210 & \multirow[t]{3}{*}{0.304} & \multirow[t]{3}{*}{0.740} \\
\hline & $\begin{array}{l}\text { Within } \\
\text { groups }\end{array}$ & 14969690715.048 & 27 & 554432989.446 & & \\
\hline & Total & 15306881327.467 & 29 & & & \\
\hline \multirow[t]{3}{*}{ Ch-Cr ratio } & $\begin{array}{l}\text { Between } \\
\text { groups }\end{array}$ & 5.712 & 2 & 2.856 & \multirow[t]{3}{*}{3.444} & \multirow[t]{3}{*}{0.047} \\
\hline & $\begin{array}{l}\text { Within } \\
\text { groups }\end{array}$ & 22.387 & 27 & .829 & & \\
\hline & Total & 28.099 & 29 & & & \\
\hline
\end{tabular}

Abbreviations: ANOVA, analysis of variance; $\mathrm{Ch}$, choline; $\mathrm{Cr}$, creatine; MRS, magnetic resonance spectroscopy; NAA, $\mathrm{N}$-acetyl aspartate.

37.77 years in our study that virtually matches with the findings of Guillamo et al, ${ }^{10}$ who found 34 years as the mean age of onset. The average age of presentation for intracranial astrocytoma was 31.15 years in Dastur's series. ${ }^{12}$

Astrocytomas commonly vary in incidence according to sex. According to Ramamurthi, ${ }^{13}$ astrocytomas are more common males (3:1). In the study of Guillamo et al, ${ }^{10}$ male:female ratio was 2.2:1. Doran and Thorell ${ }^{14}$ also mentioned about male predominance in intracranial astrocytomas having ratio of 1.44:1. Our study also found male predominance, with ratio of 2.33:1, which is consistent with other studies.

Histopathologically, our study found $33.3 \%$ of gliomas to be grade II astrocytomas, $20 \%$ to be grade III astrocytomas, and $46.7 \%$ to be grade IV astrocytomas. Nafe et $\mathrm{al}^{11}$ found $10.9,26.1$, and $63 \%$ as grades II, III, and IV gliomas, respectively, while Kaminogo et al, ${ }^{8}$ studying on 25 glioma cases, found grades II, III, and IV to be 24,12 , and $64 \%$, respectively. We found grade IV astrocytoma to be the commonest type of astrocytomas; the percentage is not as high as in the other studies.

Spectroscopic variables revealed a significant difference between the tumor grades concerning the peak for $\mathrm{Ch}$. This peak has higher values in grade III and grade IV tumors than in grade II tumors. In this study, there was persistent rise of $\mathrm{Ch}$ peak from grade II to grade IV. Concerning the comparison between different histologic tumors grades of gliomas using ${ }^{1}$ HMRS, most authors found low peak intensities of $\mathrm{Ch}$ in gliomas with a low tumor grade such as grade II astrocytomas and higher peak intensities in higher grade gliomas as the anaplastic astrocytomas and glioblastomas that are grade III and IV astrocytomas, respectively. ${ }^{11}$

Different studies found that the in vivo measurements of $\mathrm{Ch}$ in brain lesions correlate with in vitro measurements of cell density and Ch-containing substances such as phosphocholine. ${ }^{9,15}$ These compounds play an important role in cellular membrane metabolism. ${ }^{16}$ Therefore, the higher $\mathrm{Ch}$ peak seen in many ${ }^{1}$ HMRS studies on tumors of the brain has been attributed to an increased synthesis of the cell membrane and cellular density, ${ }^{11}$ which is in concordance with results of this study.

Regarding the spectroscopic variables, entire sample of cases $(n=30)$ in this study shows a tendency toward a higher NAA peak in astrocytomas grade II compared with grade III, but unexpectedly grade IV cases showed highest NAA peaks that are not supported by other studies. ${ }^{8,11}$ Since NAA is present in neuronal somata and axons, there might be some remaining neurons at the tumor border gliomas, explaining the higher NAA peak.

Cr peaks for different tumor grades were also a concern for this study. Nafe et a ${ }^{11}$ showed persistent decrease in $\mathrm{Cr}$ peak in his study. But in this study the result is nonconclusive. The peak ratios $\mathrm{Ch} / \mathrm{Cr}$ were significant in this study. There was gradual increase in $\mathrm{Ch} / \mathrm{Cr}$ ratios from lower to higher grades (grade II-IV).

The study population was divided into three groups on the basis of the grade of the tumor. Mean height of Ch, NAA, $\mathrm{Cr}$ peak, and $\mathrm{Ch} / \mathrm{Cr}$ ratio was calculated and recorded. Mean value of each variable among three grades was compared 
with ANOVA test (F-test). $F$-Value for Ch peak was 0.559 and $p$-value was 0.578 that is not significant $(p>0.05)$. F-Value for NAA peak was 0.368 and $p$-value was 0.696 that is not significant ( $p>0.05)$. $F$-Value for $\mathrm{Cr}$ peak was 0.304 and $p$-value was 0.740 that is also not significant ( $>0.05)$. F-Value for $\mathrm{Ch} / \mathrm{Cr}$ ratio was 3.444 and $p$-value was 0.047 that is significant $(p<0.05)$. This result signifies that there is a positive relationship between the Ch peak and grading of astrocytoma from grade II to IV, but the result is not significant. Relationship between the NAA, Cr peak, and grading of astrocytoma from grade II to IV is not significant. Nafe et $\mathrm{al}^{11}$ in their study found that grades III and IV gliomas have higher Ch peaks, while grade II gliomas have higher NAA peaks. The peaks for these two metabolites have significant contribution to differentiate between the grades of gliomas $(p<0.05)$. Yang et $\mathrm{al}^{1}$ found in their study that the ratios of maximum Cho/NAA, Cho/Cr, and minimum NAA/Cr are decidedly associated with tumor grade. However, glioblastomas and anaplastic gliomas cannot be differentiated significantly from these ratios.

We found in this study that there is a significant relationship between spectroscopic variables of $\mathrm{Ch} / \mathrm{Cr}$ ratio and grading of diffusely infiltrating astrocytomas. This can surely help in preoperative prediction of grading of diffusely infiltrating astrocytomas. So, MRS can be a noble modality of investigation in a developing country for preoperative assessment of prognosis and can be a good instrument for counseling.

\section{Conclusion}

In a developing country such as Bangladesh, where socioeconomic condition is not that rich, MRS can play a good role in predicting the grade as well as outcome and thus can help in counseling and management planning. Our study suggests that relationship between $\mathrm{Ch} / \mathrm{Cr}$ ratio and grading of diffusely infiltrating astrocytomas on MRS can be used as an adjunct to other investigation in the developing countries for tumor grade prediction, management planning, and counseling.

\section{Conflict of Interest}

None declared.

\section{Reference}

1 Yang D, Korogi Y, Sugahara T, et al. Cerebral gliomas: prospective comparison of multivoxel 2D chemical-shift imaging proton MR spectroscopy, echoplanar perfusion and diffusion-weighted MRI. Neuroradiology 2002; 44(8):656-666

2 Cavenee WK, Furnari FB, Huang H, et al. Astrocytic tumors. In: Kleihues P, Cavenee WK, eds. Pathology and Genetics of the Tumors of the Nervous System. 2nd edition. Lyon: Oxford University Press; 2000:314
3 Panigrahy A, Nelson MD Jr, Blüml S. Magnetic resonance spectroscopy in pediatric neuroradiology: clinical and research applications. Pediatr Radiol 2010; 40(1):3-30

4 van der Graaf M. In vivo magnetic resonance spectroscopy: basic methodology and clinical applications. Eur Biophys J 2010; 39(4):527-540

5 Burtscher IM, Holtås S. Proton magnetic resonance spectroscopy in brain tumours: clinical applications. Neuroradiology 2001; 43(5):345-352

6 Sharma U, Pal K, Pratap A, Gupta DK, Jagannathan NR. Potential of proton magnetic resonance spectroscopy in the evaluation of patients with tethered cord syndrome following surgery. J Neurosurg 2006; 105(5, Suppl):396-402

7 Sajjad Z, Alam S. Magnetic resonance spectroscopy (MRS): basic principles and applications in focal brain lesions. Pak J Neurol Sci. 2007; 2(1):42-46

8 Kaminogo M, Ishimaru H, Morikawa M, et al. Diagnostic potential of short echo time MR spectroscopy of gliomas with single-voxel and point-resolved spatially localised proton spectroscopy of brain. Neuroradiology 2001; 43(5):353-363

9 Bhakoo KK, Williams SR, Florian CL, Land H, Noble MD. Immortalization and transformation are associated with specific alterations in choline metabolism. Cancer Res 1996; 56(20):4630-4635

10 Guillamo JS, Monjour A, Taillandier L, et al; Association des Neuro-Oncologues d'Expression Française(ANOCEF). Brainstem gliomas in adults: prognostic factors and classification. Brain 2001; 124(Pt 12):2528-2539

11 Nafe R, Herminghaus S, Raab P, et al. Preoperative proton-MR spectroscopy of gliomas--correlation with quantitative nuclear morphology in surgical specimen. J Neurooncol 2003; 63(3):233-245

12 Dastur HM, Lalita VS. Intracranial tumor pathology. In: Ramamurthi B, Tandon PN, eds. Textbook of Neurosurgery. 1st edition. New Delhi: National Book Trust; 1980:733-86

13 Ramamurthi B. Gliomas. In: Ramamurthi B, Tandon PN, eds. Textbook of Neurosurgery. 2. 1 ed. New Delhi: National Books Trust; 1980:848-64

14 Doran SE, Thorell WE. Brain Tumors: population-based epidemiology, environmental risk factors, and genetic and hereditary syndromes. In: Winn HR, ed. Youmans Neurological Surgery. 2. 5 ed. Philadelphia: Saunders; 2004:807-16

15 Miller BL, Chang L, Booth R, et al. In vivo 1H MRS choline: correlation with in vitro chemistry/histology. Life Sci 1996; 58(22):1929-1935

16 Aiken NR, Gillies RJ. Phosphomonoester metabolism as a function of cell proliferative status and exogenous precursors. Anticancer Res 1996; 16(3B):1393-1397 